Article

\title{
Multi-Wavelength Based Optical Density Sensor for Autonomous Monitoring of Microalgae
}

\author{
Fei Jia ${ }^{1}$, Murat Kacira ${ }^{1, *}$ and Kimberly L. Ogden ${ }^{2}$
}

1 Department of Agricultural and Biosystems Engineering, The University of Arizona, 1177 E. 4th Street, Shantz Building, Room 403, Tucson, AZ 85721, USA; E-Mail: feijia@email.arizona.edu

2 Department of Chemical and Environmental Engineering, The University of Arizona, 1133 E James E. Rogers Way, Room 108, Tucson, AZ 85721,USA; E-Mail: ogden@email.arizona.edu

* Author to whom correspondence should be addressed; E-Mail: mkacira@email.arizona.edu; Tel.: +1-520-626-4254; Fax: +1-520-626-1700.

Academic Editor: W. Rudolf Seitz

Received: 9 July 2015 / Accepted: 25 August 2015 / Published: 2 September 2015

\begin{abstract}
A multi-wavelength based optical density sensor unit was designed, developed, and evaluated to monitor microalgae growth in real time. The system consisted of five main components including: (1) laser diode modules as light sources; (2) photodiodes as detectors; (3) driver circuit; (4) flow cell; and (5) sensor housing temperature controller. The sensor unit was designed to be integrated into any microalgae culture system for both real time and non-real time optical density measurements and algae growth monitoring applications. It was shown that the sensor unit was capable of monitoring the dynamics and physiological changes of the microalgae culture in real-time. Algae biomass concentration was accurately estimated with optical density measurements at 650,685 and $780 \mathrm{~nm}$ wavelengths used by the sensor unit. The sensor unit was able to monitor cell concentration as high as $1.05 \mathrm{~g} \cdot \mathrm{L}^{-1}$ $\left(1.51 \times 10^{8}\right.$ cells $\left.\cdot \mathrm{mL}^{-1}\right)$ during the culture growth without any sample preparation for the measurements. Since high cell concentrations do not need to be diluted using the sensor unit, the system has the potential to be used in industrial microalgae cultivation systems for real time monitoring and control applications that can lead to improved resource use efficiency.
\end{abstract}

Keywords: optical density; multi-wavelength; microalgae; real-time monitoring and control 


\section{Introduction}

Microalgae have been successfully used as feedstock for the production of pharmaceutical products, nutritional supplements and chemicals [1-4]. Certain species of microalgae are candidates for the production of biofuels due to their high productivity and high oil content [5-7]. Producing sufficient amounts of biomass with controlled quality is the premise of production of microalgae derived products. Optimizing resource inputs and maintaining high productivity are the key components to control the quantity and cost of the algae production.

Real-time monitoring and control provides the platform to acquire the environmental and physiological dynamics of a microalgae culture system. For large scale microalgae production systems, effective decision making and overall production system management in terms of optimal resource use, harvesting and culture condition optimization (media composition, lighting, temperature, $\mathrm{pH}$, dissolved oxygen levels, etc.) is crucial in order to achieve maximum profit and to prevent or reduce economic losses in case of contamination [8].

Measurements of biological variables, including cell mass concentration, cell size, cell morphology, population composition (i.e., concerns with contamination), pigments and lipid content, are especially desirable because they are the direct indicators of the dynamics of a microalgae culture system. Standard methods developed for measurements of these variables are either too laborious or destructive to be employed for real-time monitoring and control purposes $[9,10]$. Spectrophotometry has been widely used to estimate these biological variables by measuring the absorbance, turbidity or fluorescence of the culture suspension [11-13]. As a non-destructive and rapid analytical method, spectrophotometry became a preferable candidate for real-time monitoring and control of microalgae culture systems.

There are some commercialized sensors to monitor microalgae concentration [14-17]. However, most of them are designed to monitor microalgae concentration at an environmental level which is much lower than the cell concentration in microalgae production applications. Furthermore, these sensors are too expensive for low added value product applications. Therefore, they are not practical to integrate into outdoor raceway or photobioreactor based algae production systems.

There have been only few studies on development and evaluation of self-constructed optical sensors for microalgae monitoring and control applications [18-25]. For instance, Sandes et al. [23] focused on measuring the intensity of light transmitted through a transparent production tube with a $10 \mathrm{~mm}$ light path length containing a microalgae suspension using a LED $(880 \mathrm{~nm})$ and photodiode pair mounted on the opposite side of the tube. The sensor was able to estimate the cell concentration of Nannochloropsis oceanica and correlated both with dry weight (up to $2.0 \mathrm{~g} \cdot \mathrm{L}^{-1}$ ) and cell count. Briassoulis et al. [18] developed an automated flow-through density sensor and harvesting system for Nannochloropsis $\mathrm{sp}$. The LEDs paired with photosensors were used to measure the light transmittance of cell culture at 470, 518, 630 and $940 \mathrm{~nm}$. A neural network was employed to estimate biomass concentration by associating the voltage readings from each photosensor with the cell concentration measured by cell count. The sensor reported has an absolute estimation error below $8 \times 10^{6}$ cells $\cdot \mathrm{mL}^{-1}$, and a maximum error at $9 \%$ within interval of 5 to $145 \times 10^{6}$ cells $\cdot \mathrm{mL}^{-1}$. Nedbal et al. [22] described the monitoring of chlorophyll concentration and cell density of a cyanobacterial suspension by a flat-cuvette photobioreactor with a built-in fluorometer and densitometer. Blue LEDs $(455 \mathrm{~nm})$ and orange LEDs $(627 \mathrm{~nm})$ were used for excitation of blue absorption and phycobilins, respectively. The optical density of the suspension was 
measured at $680 \mathrm{~nm}$ and $735 \mathrm{~nm}$. Cell count and chlorophyll concentration were linearly proportional to optical density (OD) 680 in the range $0.1-1.2$ and to OD 735 in the range 0.02-0.4; these values of OD or cell density are typically exceeded in microalgae production systems. Furthermore, the sensor unit was designed for a specific PBR, re-configuration and re-calibration of the sensor will be necessary if it were to be integrated into other culture systems. Marxen et al. [20] developed a bioreactor system for the cultivation of Synechocystis sp. PCC6803. Dry mass of microalgae was estimated by the measurement of optical density of the suspension at $870 \mathrm{~nm}$. Chlorophyll concentration was determined by the pulse amplitude modulation (PAM) technique. Yao et al. [25] developed and tested an optical density based sensor using a LED and photodiode based unit at two wavelengths (Red and NIR) to monitor algae growth. The sensor was able to estimate biomass concentration ranging from 0.05 to $0.50 \mathrm{OD}$ in indoor conditions. The study reported temperature dependency of the sensor unit that caused inaccurate measurement of algal biomass concentration when tested in outdoor conditions.

To our knowledge, there is no current optical sensor design that exists in the market for measuring multiple biological parameters in real time both in an indoor PBR and outdoor raceway system within a high cell concentration range and without needing sample preparation (i.e., dilution, washing, filtration) prior to measurements. Therefore, we describe here the design, development and evaluation of a relatively low cost multi-wavelength laser diode-photodiode based sensor applicable for use both in an indoor photobioreactor system and an outdoor raceway system to monitor optical density and growth of microalgae in real time.

\section{Material and Methods}

\subsection{Optical Density Measurement Sensor}

The growth dynamics of the microalgae culture was measured using the real-time optical density sensor (Figure 1) developed in this study. Light absorbance of microalgae suspensions at multiple wavelengths correlate to different characters of microalgae cells. The $650(650 \mathrm{~nm}-10 \mathrm{~mW}$, US-Lasers Inc., Baldwin Park, CA, USA), 685 (HL6750MG, Oclaro Inc., San Jose, CA, USA) and 780 (780 nm-10 mW, US-Lasers Inc., Baldwin Park, CA, USA) laser diodes were used in the developed sensor unit for this study. These three wavelengths have been commonly used to estimate the cell concentration of microalgae suspension [11-13]. Light absorbance at $780 \mathrm{~nm}$ estimates the turbidity of the suspension since the color of microalgae has no effect on the absorbance, whereas, light absorbance at 650 and $685 \mathrm{~nm}$ correlates to both intensity of the color (i.e., chlorophyll content) and cell concentration.

The optical sensor unit consisted of laser diode modules as light sources, a photodiode as a detector and custom-made fixtures to house them. Laser diode modules consisted of laser diodes, driver circuit (iC-WK BMST WK2D, iC Haus LLC., Jaffrey, NH, USA) and brass housing with adjustable optical lenses (10.4 mm Module Housing Kit, US-Lasers Inc., Baldwin Park, CA, USA). An optical filter (86734, Edmund Optics Inc., Barrington, NJ, USA) was placed in front of the $685 \mathrm{~nm}$ laser diode to allow only the light with wavelength from 680 to $690 \mathrm{~nm}$ to pass through. The system design enabled adjustment of the output power of the modules by a potentiometer connected to a $5 \mathrm{~V}$ DC power source. The photodiodes (FDS100, Thorlabs Inc., Newton, NJ, USA) with a detection range of 350-1100 nm were connected to a zero-bias amplification circuit. Three pairs of laser diode modules and photodiodes 
were placed in a linear pattern in the fixture. Each pair was aligned and placed $15 \mathrm{~mm}$ apart. The diameter of the circular light beam from the laser diode modules was adjusted to be slightly smaller than the size of detection window on the photodiode. The optical sensor unit was designed to enable measurements from either standard cuvettes or custom made flow chambers with a light path length of $5 \mathrm{~mm}$. Cuvettes and flow chambers were placed perpendicular to the laser beam and $1 \mathrm{~mm}$ away from the window of photodiodes. When used for real-time monitoring, laser diodes were powered sequentially by the data logger's control module to avoid light noise from individual laser light sources. The voltage generated from the photodiodes was amplified and recorded by a data logger and controller (CR3000, Campbell Scientific Inc., UT, Logan, UT, USA). The entire sensor unit was mounted in a weather proof enclosure enabling connection of tubes for algae flow through the sensor flow cell and signal cables for the laser diodes and photo diodes.

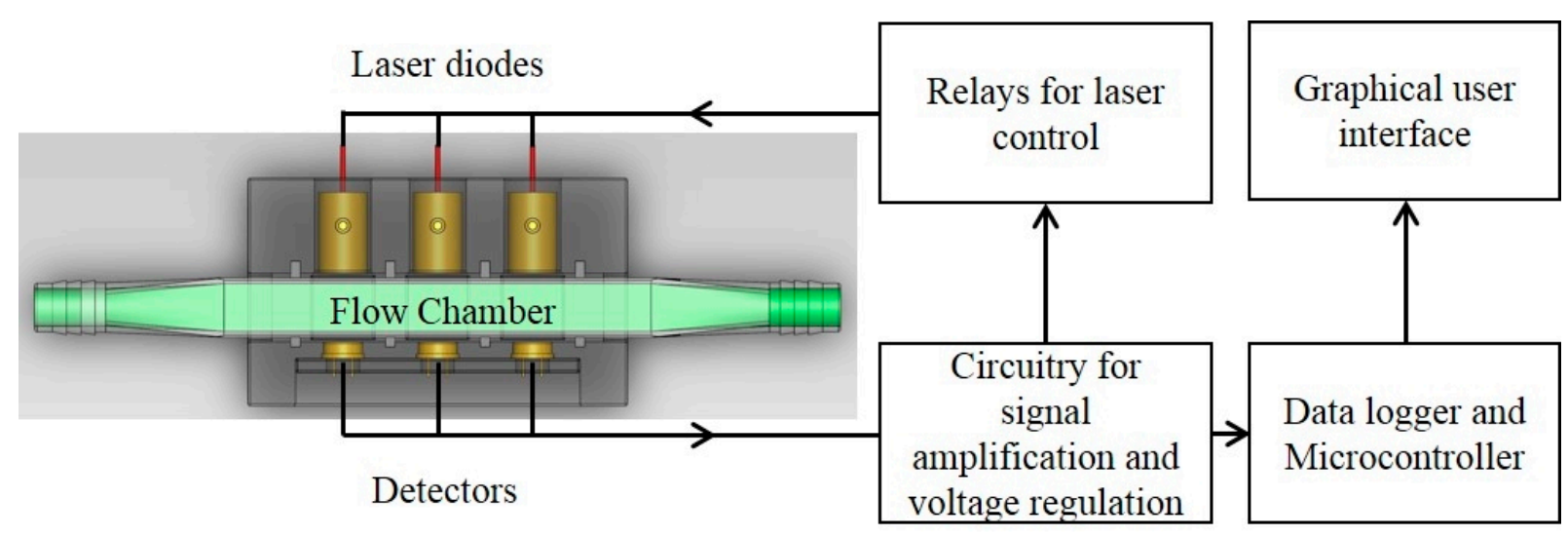

Figure 1. Component layout of the optical sensor unit. Three laser diodes at wavelengths of $650 \mathrm{~nm}, 685 \mathrm{~nm}$ and $780 \mathrm{~nm}$ were aligned with 3 photodiodes with a detection range of $350-1100 \mathrm{~nm}$. The flow chamber window was perpendicular to the laser beam.

The voltage output of the photodiode is proportional to the intensity of incident light. According to Beer-Lambert law, the light absorbance of the sample was determined by,

$$
A b s=-\ln \left(V_{s} / V_{b}\right)
$$

$A b s=$ Light absorbance;

$V_{b}=$ Output of the photodiode from growth media $(\mathrm{mV})$;

$V_{s}=$ Output of the photodiode from a sample $(\mathrm{mV})$.

\subsection{Cultivation Conditions and Organisms}

\subsubsection{Indoor Photobioreactor (PBR) Cultivation}

Chlorella sorokiniana (DOE 1412) received from Pacific Northwest National Laboratory, Richland, WA, USA [26] was cultivated in local well water enriched with Peters professional ${ }^{\circledR}$ 20-20-20 general purpose water soluble fertilizer $0.26 \mathrm{~g} \cdot \mathrm{L}^{-1}$, Citraplex $20 \%$ iron $0.053 \mathrm{~g} \cdot \mathrm{L}^{-1}$ (Citraplex 20\% Iron, Loveland Products Inc., Loveland, CO, USA) and trace elements solution $\left(\mathrm{H}_{3} \mathrm{BO}_{3} 0.0029 \mathrm{~g} \cdot \mathrm{L}^{-1}\right.$, $\mathrm{MnCl}_{2} \bullet 4 \mathrm{H}_{2} \mathrm{O} 0.0018 \mathrm{~g} \cdot \mathrm{L}^{-1}, \mathrm{ZnSO}_{4} \bullet \mathrm{H}_{2} \mathrm{O} 0.00014 \mathrm{~g} \cdot \mathrm{L}^{-1}, \mathrm{Na}_{2} \mathrm{MoO}_{4} \cdot 2 \mathrm{H}_{2} \mathrm{O} 0.00039 \mathrm{~g} \cdot \mathrm{L}^{-1}, \mathrm{CoCl}_{2} \bullet 6 \mathrm{H}_{2} \mathrm{O}$ 
$0.000055 \mathrm{~g} \cdot \mathrm{L}^{-1}$ ) under illumination intensity of $200 \mu \mathrm{mol} \cdot \mathrm{m}^{-2} \cdot \mathrm{s}^{-1}$ or $400 \mu \mathrm{mol} \cdot \mathrm{m}^{-2} \cdot \mathrm{s}^{-1}$ in rectangular air lift photo bioreactors (PBRs). The algae culture temperature was light intensity dependent and was stabilized at $30 \pm 2{ }^{\circ} \mathrm{C}$. The $\mathrm{pH}$ of the medium was controlled at $7 \pm 0.3$ by injecting $\mathrm{CO}_{2}$ from a pressurized liquid $\mathrm{CO}_{2}$ tank into PBRs.

\subsubsection{Outdoor Open Pond Raceway Cultivation}

Scenedesmus obliquus was used in the outdoor open pond raceway cultivation experiments. Scenedesmus obliquus was received from Texas A\&M AgriLife Research (Pecos, Texas, USA) and was cultivated in local well water enriched with Pecos medium, trace metal solution and $5 \mathrm{~g} \cdot \mathrm{L}^{-1} \mathrm{NaCl}$. The Pecos medium contained $0.1 \mathrm{~g} \cdot \mathrm{L}^{-1}$ urea $\left(\left(\mathrm{NH}_{2}\right)_{2} \mathrm{CO}\right), 0.012 \mathrm{~g} \cdot \mathrm{L}^{-1} \mathrm{MgSO}_{4} \cdot 7 \mathrm{H}_{2} \mathrm{O}, 0.035 \mathrm{~g} \cdot \mathrm{L}^{-1} \mathrm{NH}_{4} \mathrm{H}_{2} \mathrm{PO}_{4}$, $0.175 \mathrm{~g} \cdot \mathrm{L}^{-1}$ Potash $(\mathrm{KCl}), 0.0054 \mathrm{~g} \cdot \mathrm{L}^{-1} \mathrm{FeCl}_{3}$ and $0.02 \mathrm{~g} \cdot \mathrm{L}^{-1} \mathrm{Na}_{2} \mathrm{CO}_{3}$. The culture was maintained in an open pond paddle wheel raceway with a surface area of $3 \mathrm{~m}^{2}$ located in Tucson, Arizona, USA. The culture depth was maintained at $10 \mathrm{~cm}$ and increased to $15 \mathrm{~cm}$ later in the experiment. The $\mathrm{pH}$ of the medium was controlled at $8 \pm 0.05$ by injecting $95 \% \mathrm{CO}_{2}$ through an air sparger.

\subsection{Offline Biomass Concentration Measurement}

Biomass concentration of microalgae was determined by both cell counting and ash-free dry weight (AFDW) measurements. Cell suspension was diluted to a concentration between $10^{6}$ and $10^{7}$ cells $\cdot \mathrm{mL}^{-1}$ for cell counting by a neubauer chamber hemocytometer (Hy-Lite Ultra-plane, Clayadams, Franklin Lakes, NJ, USA) under a microscope (XSZ-138, AOK International Group Ltd., Shanghai, China). The AFDW of the cells was measured following the method described by Zhu and Lee (1997) [27]. The light absorbance of the cells suspension was measured at 650, 685, 750 and $780 \mathrm{~nm}$ by a spectrophotometer (DR 3800, HACH, Loveland, CO, USA) using a $10 \mathrm{~mm}$ light path length cuvette. Samples were diluted with deionized water when necessary to keep the absorbance reading below 0.5 .

\subsection{Real-Time Monitoring of Microalgae Growth Dynamics}

\subsubsection{Indoor PBR Cultivation}

The microalgae culture system consisted of an air lift flat panel PBR illuminated by a fluorescent lighting system. The pH (HI1001, Hanna Instruments, Woonsocket, RI, USA), electrical conductivity (HI3001, Hanna Instruments, Woonsocket, RI, USA), dissolved oxygen (DO1200/T, Sensorex, Garden Grove, CA, USA) and thermocouple temperature probes (Type T, Omega Engineering Inc., Stamford, CT, USA) were placed in the PBR for monitoring and control by a CR3000 datalogger. Each sensor was scanned every second and 10 minute averaged data was stored in the datalogger.

Flat panel PBRs with dimensions of $61(\mathrm{H}) \times 61(\mathrm{~L}) \times 7.6 \mathrm{~cm}(\mathrm{~W})$ were built using $6.35 \mathrm{~mm}$ thick clear acrylic panels (ACRYCLR0.250PM48X48, Plexiglas, San Diego, CA, USA). Air was constantly injected into the PBR via a $45.7 \mathrm{~cm}$ long air sparger mounted at the bottom of PBR for aeration and to achieve proper mixing of the microalgae culture. Carbon dioxide injection was controlled by the datalogger to maintain a desired $\mathrm{pH}$ level $(7 \pm 0.3)$ in the PBR. The lighting system consisted of sixteen $61 \mathrm{~cm} \mathrm{17-watt}$ fluorescent light tubes (F17T8/741, Litetronics International, Inc., Harvey, IL, USA) mounted on a supporting structure. Two levels of light intensity $\left(200\right.$ and $\left.400 \mu \mathrm{mols} \cdot \mathrm{m}^{-2} \cdot \mathrm{s}^{-1}\right)$ were achieved by adjusting 
the number of lights used. The light remained on 24 hours per day, no dark period was used. A small centrifugal pump (Seltz 20, Hydor, Sacramento, CA, USA) was used to recirculate cell suspension through the inline optical density measurement unit for the PBR. The optical density sensor was connected to the PBR system for continuous monitoring of OD and microalgae growth (Figure 2).

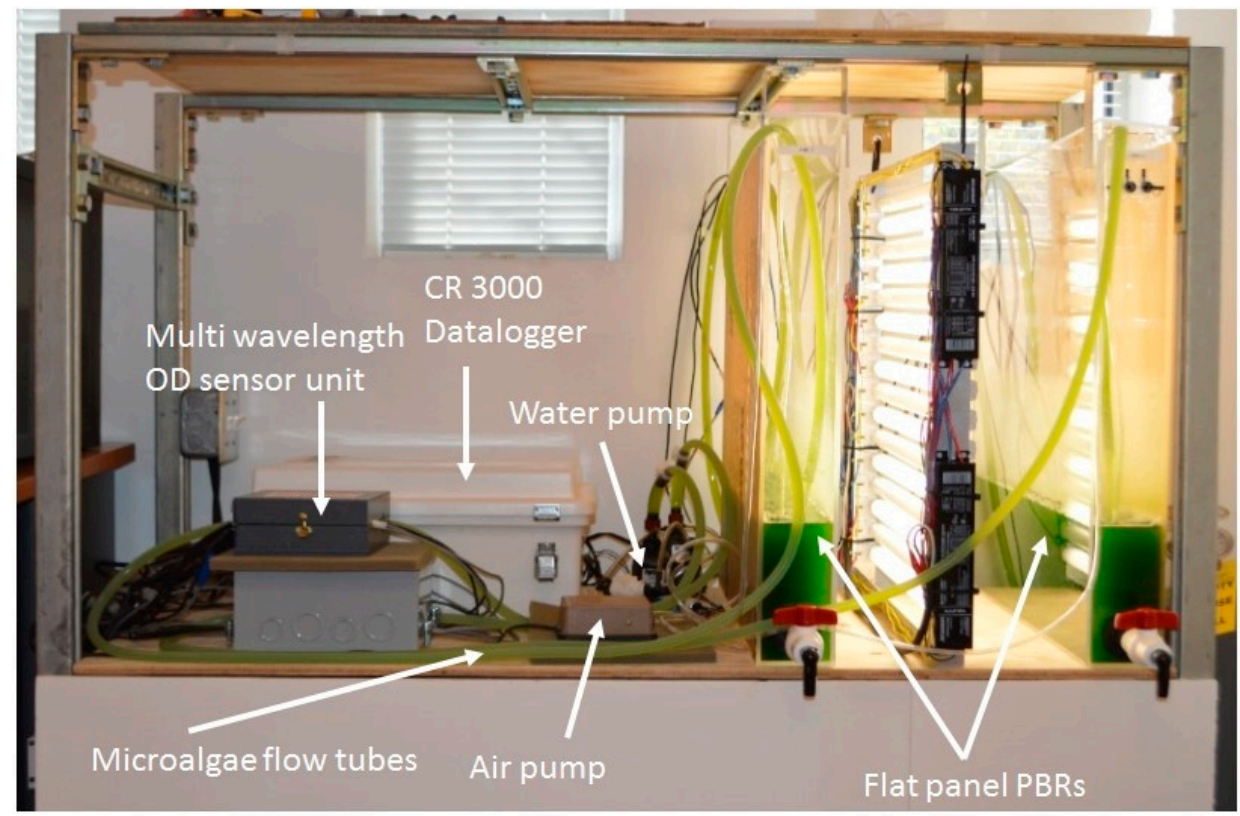

Figure 2. Multi wavelength optical sensor integrated into air-lift flat panel photobioreactors for real-time microalgae growth monitoring.

\subsubsection{Outdoor Open Pond Raceway Cultivation}

The optical density sensor was also integrated into an outdoor raceway system for continuous monitoring of microalgae growth (Figure 3). Since sensor electronics maybe sensitive to environmental conditions, the optical sensor with its housing and the datalogger were placed in a location at the outdoor raceway site to minimize direct exposure to sunlight. The laser output is also temperature dependent $\left(5-15 \mathrm{mV} /{ }^{\circ} \mathrm{C}\right.$, vary with lasers). Therefore a temperature control unit was installed and consisted of a small heater plate (HT24S, Thorlabs, Newton, NJ, USA) and heat sink (55 mm Fan Heatsink, Amazon.com, USA) to maintain a constant temperature $\left(25 \pm 0.1^{\circ} \mathrm{C}\right)$ inside the sensor box. This also ensured a constant laser power output. The paddle wheel in the raceway system was operated 24 hours a day for continuous culture mixing. The $\mathrm{CO}_{2}$ injection was turned off during night time. In addition to the measurement data collected for the indoor experiment, photosynthetically active radiation (PAR) was also measured using a quantum sensor (SQ-110, Apogee instruments, Logan, UT, USA) at the level of the raceway system. All variables were recorded at the same frequency for sensor scanning and data averaging as described for the indoor cultivation experiment. The experiment occurred from $2 / 25$ to $3 / 15$ for a total of 18 days. 


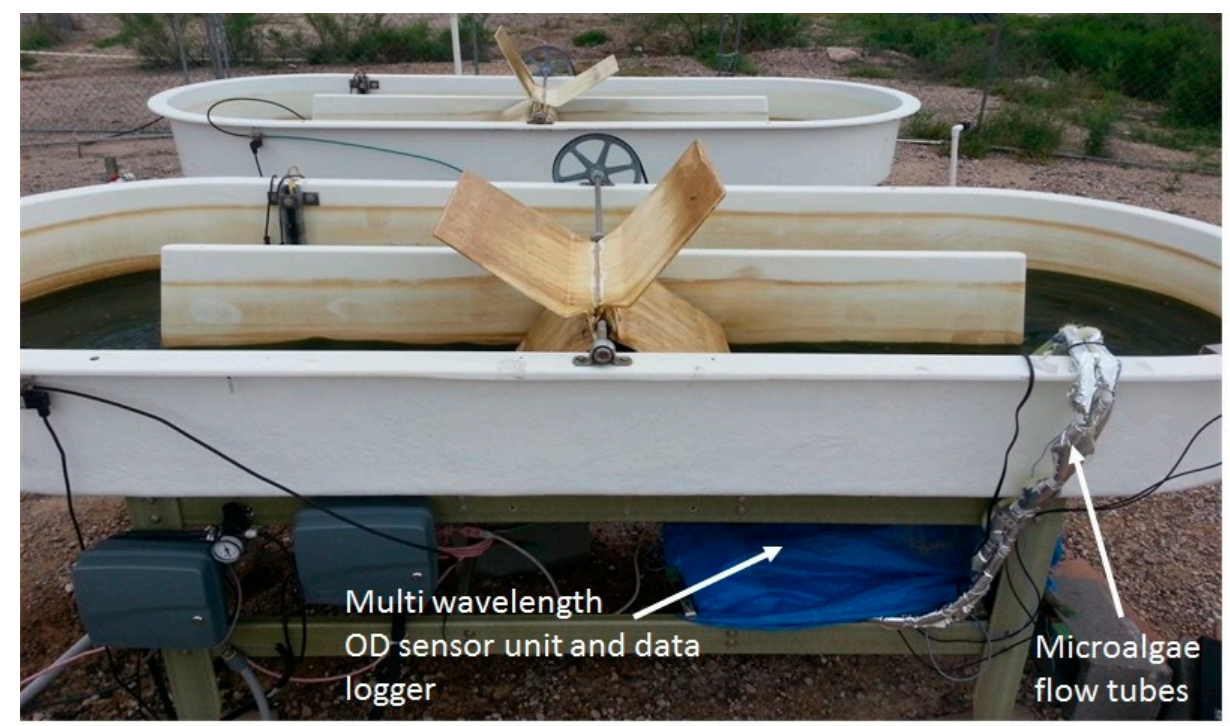

Figure 3. Optical sensor integrated into an open pond raceway for real-time microalgae growth monitoring.

\section{Results and Discussion}

\subsection{In Situ Calibration of the Optical Density Measurement Unit}

Light absorbance from a flowing cell suspension can be different from static samples due to cell movement and potentially the presence of fine air bubbles. Therefore, a calibration of the unit using flowing microalgae culture is necessary. In order to achieve in-line real-time monitoring, sample preparation needs to be eliminated or automated. In this study, flow chambers with light path lengths of $5 \mathrm{~mm}$ were used to extend the measurement range of the unit without requiring sample dilution.

The optical sensor unit (Figure 1) developed in this study (referred as IOS hereafter) was calibrated by comparing the reading from the sensor unit to that from a bench-top spectrophotometer (referred as BT hereafter) at 650, 685 and $780 \mathrm{~nm}$. The bench-top spectrophotometer (DR3800, Hach, CO, USA) was calibrated to both ash-free dry weight (AFDW) and cell count (CC) for C. sorokiniana at all three wavelengths: $A F D W=0.188 \times \mathrm{OD}_{650}+0.0453 \mathrm{~g} \cdot \mathrm{L}^{-1}\left(\mathrm{R}^{2}=0.96\right), \mathrm{AFDW}=0.161 \times \mathrm{OD}_{685}+0.0292 \mathrm{~g} \cdot \mathrm{L}^{-1}$ $\left(\mathrm{R}^{2}=0.96\right)$, AFDW $=0.205 \times \mathrm{OD}_{780}+0.0546 \mathrm{~g} \cdot \mathrm{L}^{-1}\left(\mathrm{R}^{2}=0.95\right), \mathrm{CC}=\left(28.6 \times \mathrm{OD}_{650}+1.13\right) \times$ $10^{6}$ cells $\cdot \mathrm{mL}^{-1}\left(\mathrm{R}^{2}=0.91\right), \mathrm{CC}=\left(26.8 \times \mathrm{OD}_{685}-3.92\right) \times 10^{6}$ cells $\cdot \mathrm{mL}^{-1}\left(\mathrm{R}^{2}=0.95\right)$, $\mathrm{CC}=\left(29.8 \times \mathrm{OD}_{780}+3.96\right) \times 10^{6}$ cells $\cdot \mathrm{mL}^{-1}\left(\mathrm{R}^{2}=0.90\right)$. The optical density readings measured from the spectrophotometer using standard $10 \mathrm{~mm}$ cuvettes were compared to the results obtained from optical sensor unit using $5 \mathrm{~mm}$ flow cell. Strong linear correlations between the two measurement units were obtained at all wavelengths examined (Figure 4). A linear correlation was tightly followed $\left(\mathrm{R}^{2}=0.99\right)$ between the optical density measurements obtained from IOS and BT units at $780 \mathrm{~nm}$ with cell concentration up to $1.05 \mathrm{~g} \cdot \mathrm{L}^{-1}\left(1.51 \times 10^{8}\right.$ cells $\left.\cdot \mathrm{mL}^{-1}\right)$. Linear correlations hold for OD $650\left(\mathrm{R}^{2}=0.98\right)$ and $\mathrm{OD}_{685}\left(\mathrm{R}^{2}=0.99\right)$ for cell concentrations below $0.592 \mathrm{~g} \cdot \mathrm{L}^{-1}$. However, beyond this range while below $1.05 \mathrm{~g} \cdot \mathrm{L}^{-1}$, different linear correlations were observed for these two wavelengths (Figure 4). Compared to the results from Nedbal et al. [22], the optical sensor unit showed the capability of measuring cell concentration over a wide range without dilution of the samples. The same calibration procedure was performed for $S$. obliquus during outdoor testing. 


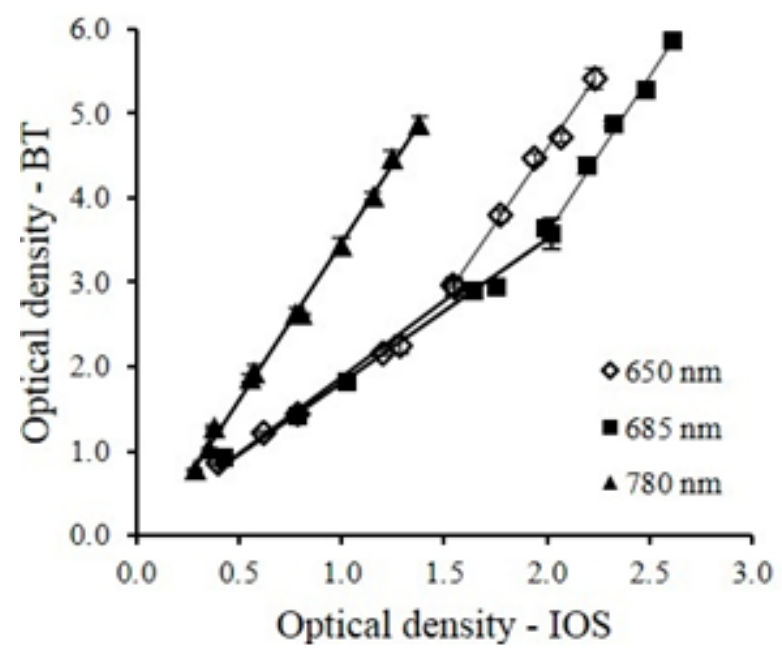

(a)

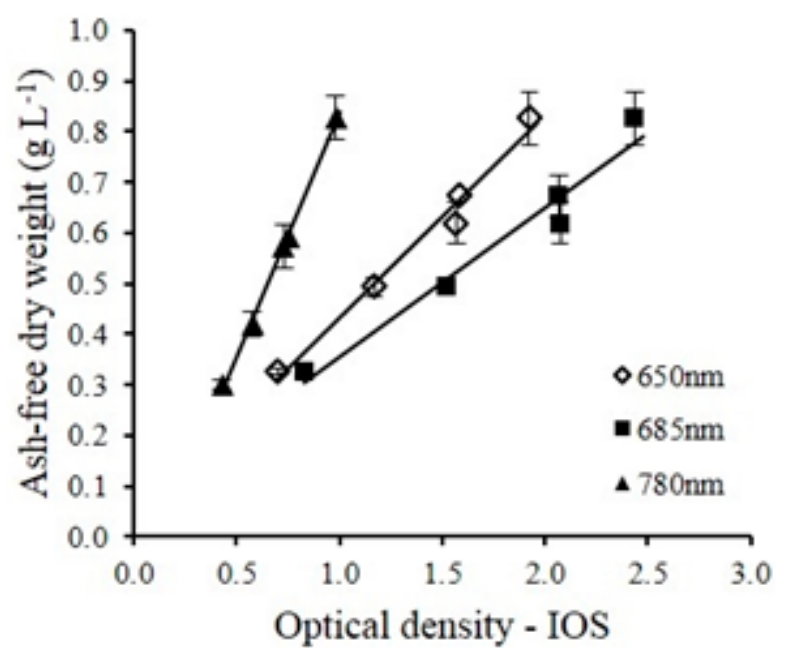

(b)

Figure 4. (a) Correlation between the optical densities of DOE 1412 in the PBR measured by a bench-top spectrophotometer (BT) and by the inline optical sensors (IOS). $\mathrm{OD}_{650(\mathrm{BT})}=1.82 \times \mathrm{OD}_{650(\mathrm{IOS})}+0.056\left(\mathrm{AFDW}<0.592 \mathrm{~g} \cdot \mathrm{L}^{-1}\right), \mathrm{OD}_{685}(\mathrm{BT})=1.70 \times \mathrm{OD}_{685}(\mathrm{IOS})$ $+0.11\left(\mathrm{AFDW}<0.592 \mathrm{~g} \cdot \mathrm{L}^{-1}\right), \mathrm{OD}_{650}(\mathrm{BT})=3.54 \times \mathrm{OD}_{650}(\mathrm{IOS})-2.51\left(0.592 \mathrm{~g} \cdot \mathrm{L}^{-1}<\mathrm{AFDW}\right.$ $\left.<1.05 \mathrm{~g} \cdot \mathrm{L}^{-1}\right), \mathrm{OD}_{685}(\mathrm{BT})=3.72 \times \mathrm{OD}_{685}(\mathrm{IOS})-3.88\left(0.592 \mathrm{~g} \cdot \mathrm{L}^{-1}<\mathrm{AFDW}<1.05 \mathrm{~g} \cdot \mathrm{L}^{-1}\right)$, $\mathrm{OD}_{780}(\mathrm{BT})=3.71 \times \mathrm{OD}_{780}(\mathrm{IOS})-0.2445\left(\mathrm{AFDW}<1.05 \mathrm{~g} \cdot \mathrm{L}^{-1}\right)$. (b) Correlation between optical density $(\mathrm{IOS})$ and AFDW, AFDW $=0.96 \times \mathrm{OD}_{780}(\mathrm{IOS})-0.12\left(\mathrm{R}^{2}=0.99\right)$; AFDW $=$ $0.40 \times \mathrm{OD}_{650(\mathrm{IOS})}+0.032\left(\mathrm{R}^{2}=0.98\right) ; \mathrm{AFDW}=0.30 \times \mathrm{OD}_{685}(\mathrm{IOS})+0.061\left(\mathrm{R}^{2}=0.96\right)$.

The OD readings from the optical sensor unit measured using $5 \mathrm{~mm}$ path length flow cell should be half of that from the spectrophotometer using a standard $10 \mathrm{~mm}$ cuvette in theory. However, the results did not show an exact correlation between the two units. This was because of the light quality from the laser diodes wasn't the same as that in a spectrophotometer where a monochromatic light was generated. Figure 5 shows the spectra of the laser diodes used in the developed sensor unit, measured by a spectroradiometer (PS-300, Apogee Instruments, Logan, UT, USA) and the optical density spectra of DOE 1412. The peak wavelengths of each laser diode were slightly shifted from what was claimed by the manufacturers. An optical filter (86734, Edmund Optics, Barrington, NJ, USA) was used to narrow the band width of $685 \mathrm{~nm}$ laser diode from $80 \mathrm{~nm}$ to $10 \mathrm{~nm}$ and corrected the peak wavelength back to $685 \mathrm{~nm}$ from $688 \mathrm{~nm}$. Despite the inferiority of the light beam generated from laser diodes, the strong linear correlations proved that the optical sensor unit was able to estimate the cell density as accurate as a spectrophotometer via calibration (Figure 4). 


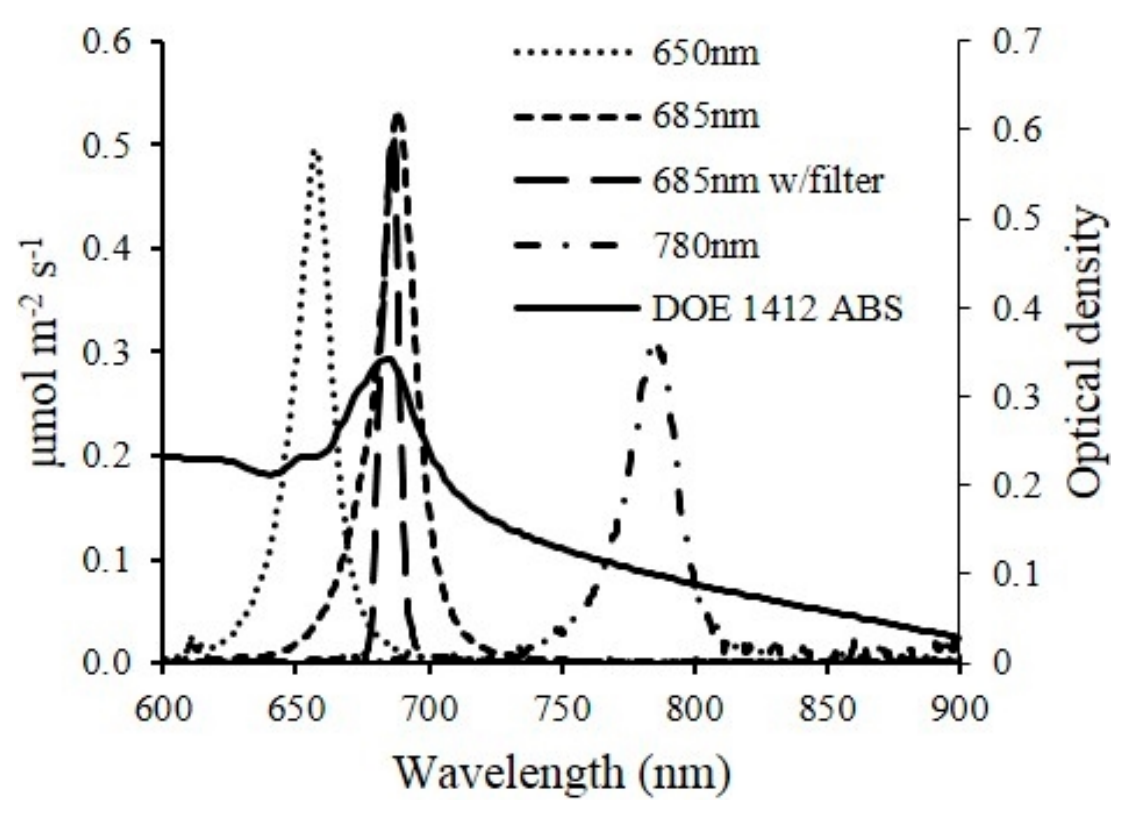

Figure 5. Light absorbance spectrum of DOE 1412 and light spectra of laser diodes used on the optical sensor.

\subsection{Real-Time Microalgae Growth Monitoring}

The optical sensor unit along with other sensors to monitor algae culture environment was integrated into a PBR to monitor the dynamics of a microalgae culture system. Figure 6 a shows the growth dynamics of semi-continuous culture of DOE 1412 as measured by the optical sensor unit over a period of 10 days. Sensor output shown in Figure 6a was calibrated to optical density reading from a bench-top spectrophotometer. The optical sensor unit showed the capability to capture the growth phases during semi-continuous operation, and the sudden change of cell concentration due to harvesting and addition of fresh media (indicated with arrows on the Figure). A maximum cell concentration of $1.05 \mathrm{~g} \cdot \mathrm{L}^{-1}$ $\left(1.51 \times 10^{8}\right.$ cells $\left.\cdot \mathrm{mL}^{-1}\right)$ was observed during the cultivation experiment without any sample preparation and dilution for the measurements.

Growth dynamics of the microalgae was quantified by the growth rate. The growth rate was determined by the following equation with $\Delta \mathrm{t}$ of 2 hours ( 0.08 days).

$$
\mu=\frac{\ln \left(O D_{2}\right)_{\lambda}-\ln \left(O D_{1}\right)_{\lambda}}{\Delta t}
$$

$\mu \quad=$ Growth rate $\left(\right.$ day $\left.^{-1}\right)$;

$\mathrm{OD}=$ Optical density of microalgae at different time points $(\lambda=780 \mathrm{~nm})$;

$\Delta \mathrm{t}=$ Difference between the two time points (day).

The change of growth rate was clearly demonstrated by plotting the growth rate $(\mu)$ of DOE 1412 over time (Figure 6b). The initial lag phase was followed by an increase in cell growth. Microalgae culture reached maximum growth rate soon after the lag phase when there is no light limitation. The growth rate then gradually decreases as the culture becomes light limited. When the illumination intensity was increased from $200 \mu \mathrm{mol} \cdot \mathrm{m}^{-2} \cdot \mathrm{s}^{-1}$ to $400 \mu \mathrm{mol} \cdot \mathrm{m}^{-2} \cdot \mathrm{s}^{-1}$ on 3 February 2014 an increase in growth rate was observed (Figure 6b). The growth rate dropped down to the level prior the alternation of light intensity as the culture again became light limited. These events were detected by the optical 
sensor unit (Figure 6a,b). Although real time growth rate is not required for microalgal biomass production purposes, data with such high resolution provided a great tool for studying the fast response of microalgae to sudden change of the environmental conditions.
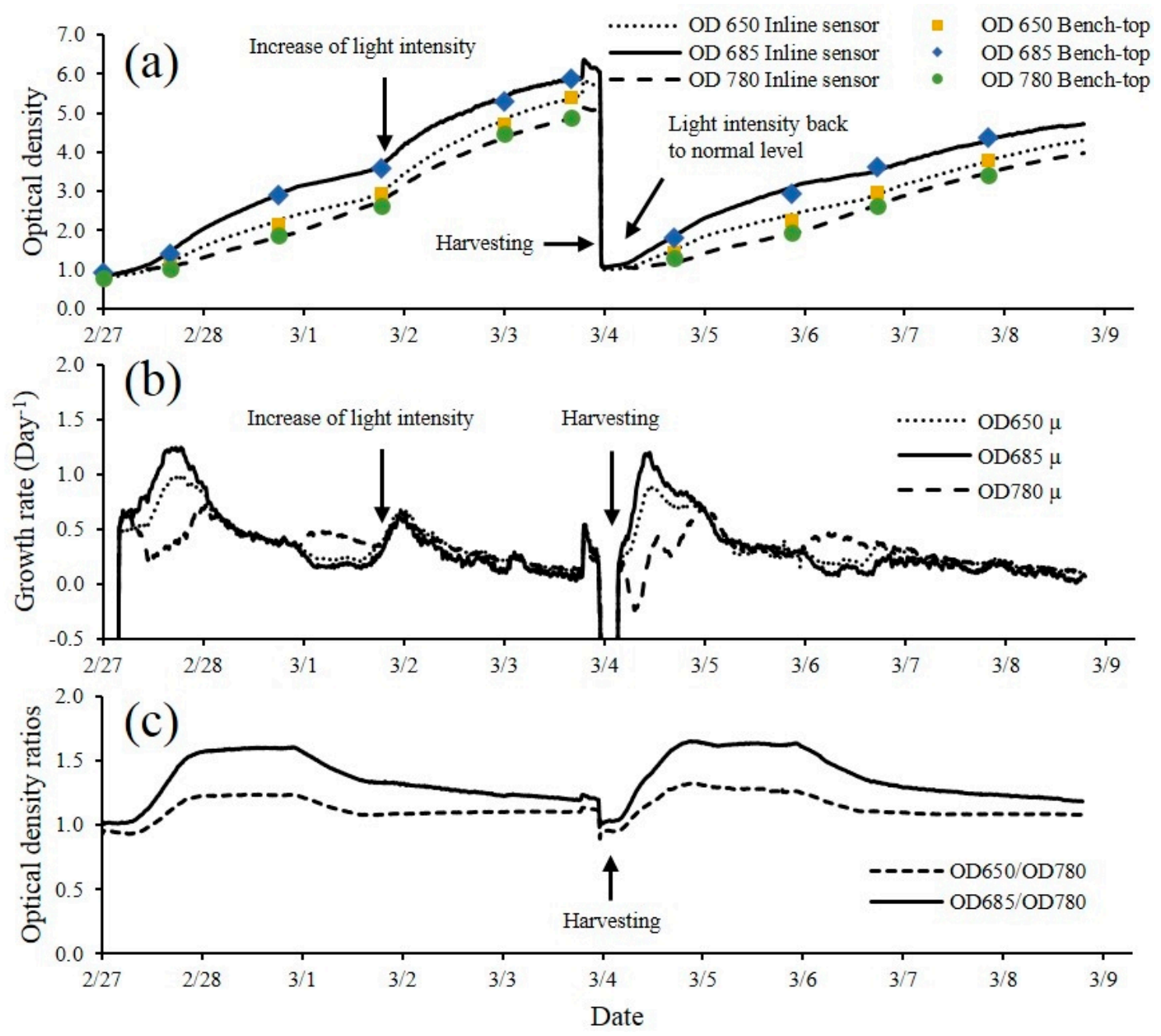

Figure 6. (a) Dynamics of optical density at $650 \mathrm{~nm}, 685 \mathrm{~nm}$ and $780 \mathrm{~nm}$ during semi-continuous culture of DOE 1412 run for 10 days. Illumination intensity was increased from $200 \mu \mathrm{mol} \cdot \mathrm{m}^{-2} \cdot \mathrm{s}^{-1}$ to $400 \mu \mathrm{mol} \cdot \mathrm{m}^{-2} \cdot \mathrm{s}^{-1}$ during the first batch on $3 / 2$, it was then reduced to $200 \mu \mathrm{mol} \cdot \mathrm{m}^{-2} \cdot \mathrm{s}^{-1}$ by the end of the batch; (b) Growth rate of DOE 1412 at 650,685 and $780 \mathrm{~nm}$ and (c) ratios of optical densities at $650 / 780 \mathrm{~nm}$ and $685 / 780 \mathrm{~nm}$.

Monitoring not only the cell concentration change, but also the dynamic physiological status of the microalgae culture including the changes in growth rate and the change of chlorophyll content can serve as indicators of the health of the culture. This is important for cultivation of microalgae production when it is desirable to control conditions to produce a product of interest. For example, some microalgae produce more lipids when nutrients such as nitrogen are limiting. The ratios of optical densities at different wavelengths $(685 / 780 \mathrm{~nm}$ and 650/780 nm) are shown in Figure 6c. The ratios remained constant during lag phase, followed by a rapid increase during the exponential growth phase and stabilized at a higher level throughout the linear growth phase. The ratios then started to decrease as the growth of cells slowed down which indicated the transition from linear to stationary phase. The pattern of the ratio change occurred 
repeatedly over the time course of the experiment regardless of the growth pattern change induced by increased light intensity during the first batch. Signaling of this transition indicated that there is a decrease of chlorophyll content which absorbs most of the red light during the period indicated by the decreasing optical density ratios [28]. This might have been due to nitrogen limitation, since nitrogen is often rapidly consumed by algal cells during exponential growth according to López et al. [19]. Similar results for the change of OD 680/ OD 735 was reported by Nedbal et al. [22].

The optical sensor unit was also integrated into an outdoor open pond raceway for stability testing under highly dynamic outdoor weather conditions such as large temperature variations between daytime and nighttime periods. For instance, a $20{ }^{\circ} \mathrm{C}$ temperature difference were measured inside sensor box from daytime to nighttime when the temperature control system was not activated. The optical density of the culture of $S$. obliquus during a period of 18 days recorded by the optical sensor is shown in Figure 7. The real-time optical density shows repeatedly an increase OD reading indicating the biomass increase during the day time due to photosynthesis. A small decrease in optical density was observed during the nighttime since photosynthetic microorganisms metabolize intracellular carbohydrate to sustain their metabolic activity as described by Ogbonna and Tanaka [29]. Sudden decreases of optical density of the culture due to water addition, precipitation (rain) and biomass harvesting were clearly shown in the Figure 7 labeled by arrows.

The growth rate of $S$. obliquus was compared to photosynthetic active radiation (PAR) measured at the raceway (Figure 8). The growth rate of S. obliquus was dependent on the PAR level except during the water addition time period. This set of high resolution data enables one to evaluate in detail about how $S$. obliquus responds to solar radiation level in a sunny day. The correlation between PAR and growth rate can be used for the prediction of biomass production rate based on historical weather data for a given region.

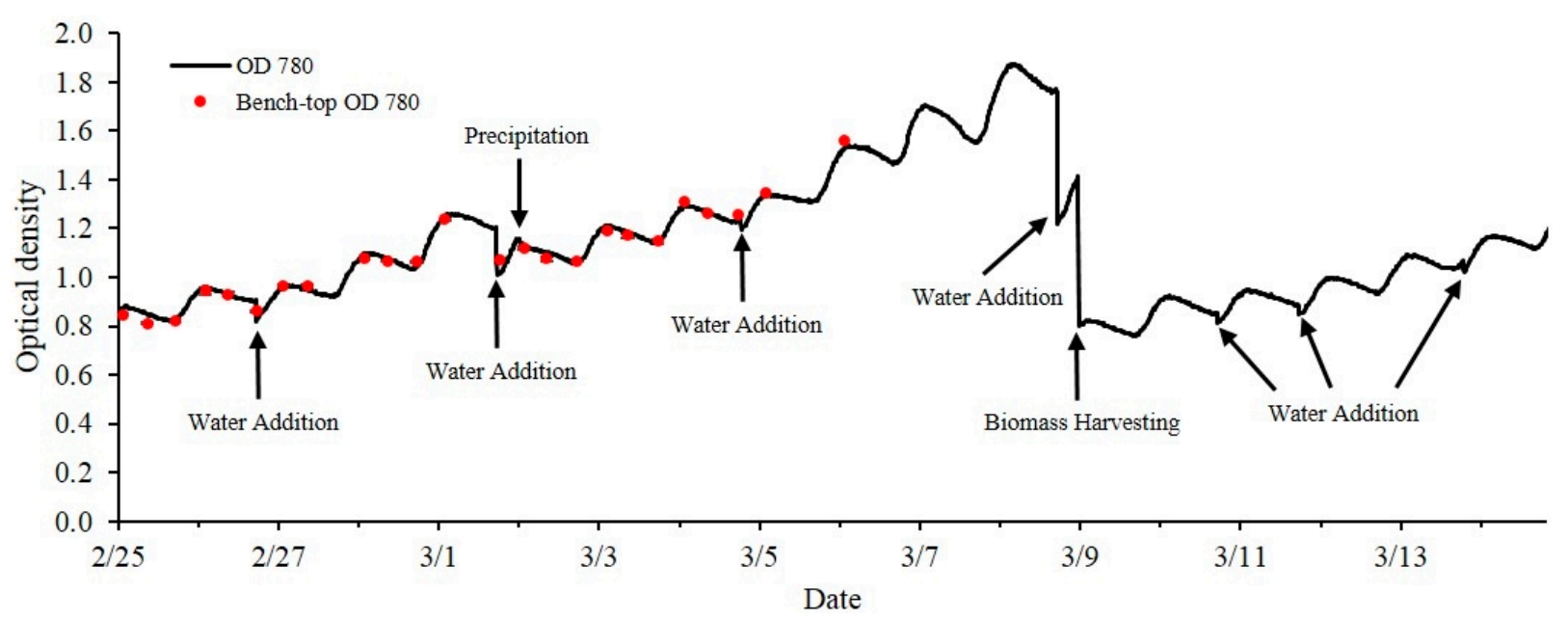

Figure 7. Optical density change of $S$. obliquus in open pond raceway over 18 days. Black arrows indicate events of water addition, precipitation and biomass harvesting. 

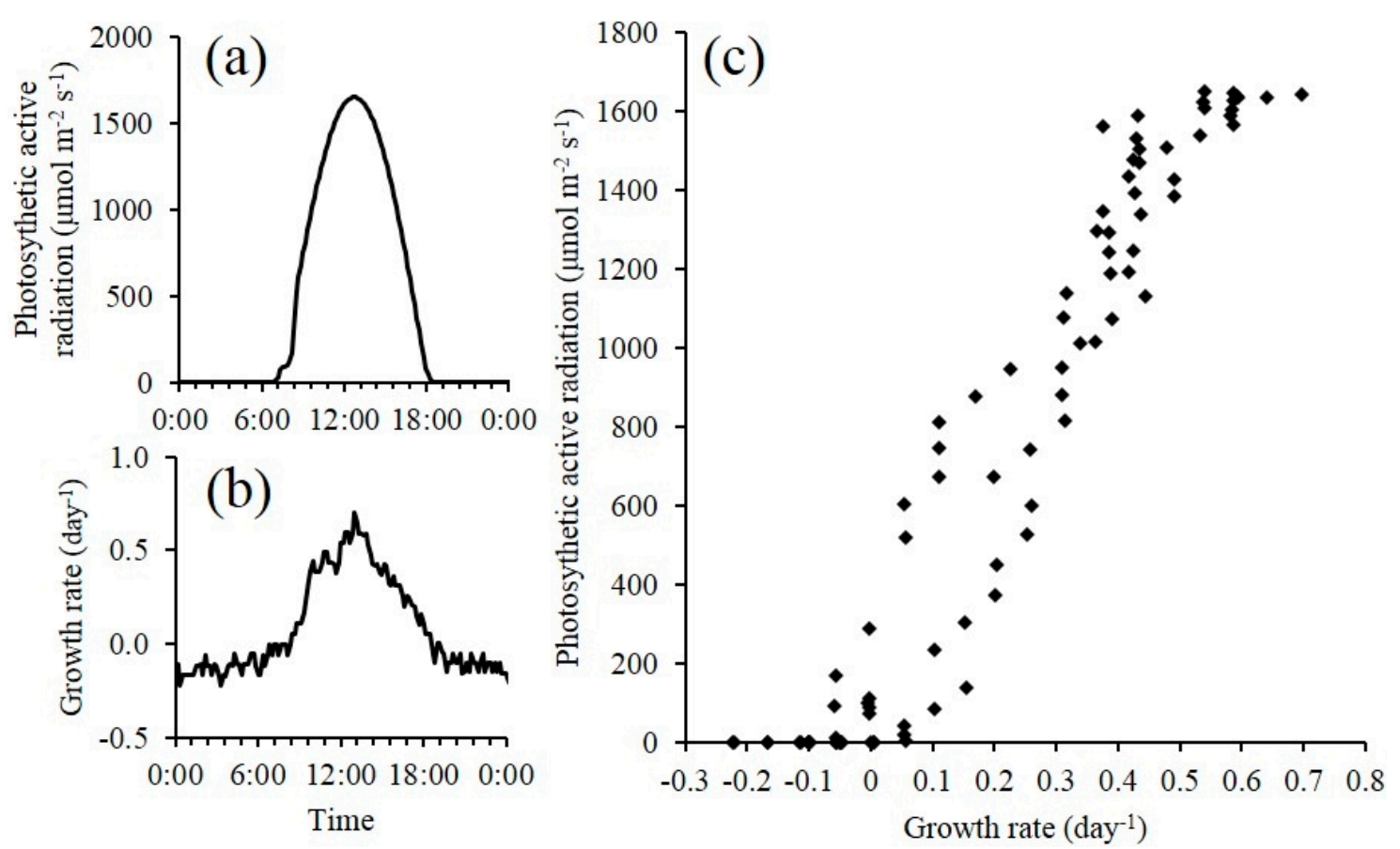

Figure 8. (a) Photosynthetic active radiation (PAR) of a sunny day in Tucson, AZ, USA; (b) Growth rate ( $\mu$ ) of $S$. obliquus in open pond raceway of the same day; (c) Scattered plot of PAR and $\mu$ from the data presented in $(\mathbf{a}, \mathbf{b})$.

\section{Conclusions}

The multi-wavelength laser diode based optical sensor unit was designed, developed and evaluated for the monitoring of microalgae culture dynamics in real-time both in a PBR and in an outdoor raceway system. The optical sensor unit prototype demonstrated the capability of estimating cell concentration and changes of the physiological status of the microalgae culture in real-time. The sensor unit was operated continuously for 18 days without any visible microalgae biofilm deposit observed on the flow chamber of the sensor unit. In this design, the only sensor hardware part that had contact with culture medium was the flow chamber which can be easily replaced. For industrial microalgae production, the application of ultra-hydrophobic material (Hydrophobic glass coating, Ultra Tech International, Inc., Jacksonville, FL, USA) on the surface of flow chamber can further extend the maintenance interval. Biomass concentration was accurately estimated by optical density measurement at 650, 685 and $780 \mathrm{~nm}$ wavelengths. The sensor was capable of measuring maximum optical density of 5.41, 5.86 and 4.88 without sample preparation at $650 \mathrm{~nm}, 685 \mathrm{~nm}$ and $780 \mathrm{~nm}$ respectively. Growth rates and ratios calculated from optical density at each wavelength were good indications for monitoring of microalgae growth transitions and for detection of disturbances to the culture system (i.e., change of light intensity, water addition, rain, and harvesting). A temperature control device for the sensor is necessary, especially for outdoor applications where air temperature can vary significantly, since the output power of laser diodes were temperature dependent. The cell concentration measurement range can be further improved by shortening the light path length of the flow chamber. Other laser modules and wavelengths of interest can be added to expand the number of biological variables measured by the sensor which is our focus for future studies. The real-time monitoring data from the optical sensor can be valuable for microalgae 
modeling studies both for PBR and outdoor raceway based production systems. With proper calibration, installation and operation, the optical sensor described in this study can be integrated into microalgae culture systems for monitoring and control purposes at a relative low cost to ultimately help optimize product quality and quantity.

\section{Acknowledgments}

This research was supported by research grant no DE-EE0006269 from The United States of America Department of Energy.

\section{Author Contributions}

Fei Jia and Murat Kacira conceived the original idea, approach and design of the optical sensor unit described in the paper. Kimberly Ogden contributed to the sensor design. Fei Jia designed and fabricated the sensor unit, performed all experiments, analyzed the data, and wrote the manuscript. Murat Kacira and Kimberly Ogden reviewed the paper and provided inputs for its revisions.

\section{Conflicts of Interest}

The authors declare no conflict of interest.

\section{References}

1. Harun, R.; Singh, M.; Forde, G.M.; Danquah, M.K. Bioprocess engineering of microalgae to produce a variety of consumer products. Renew. Sust. Energ. Rev. 2010, 14, 1037-1047.

2. Perez-Garcia, O.; Escalante, F.M.E.; de-Bashan, L.E.; Bashan, Y. Heterotrophic cultures of microalgae: Metabolism and potential products. Water Res. 2011, 45, 11-36.

3. Wiltshire, K.; Boersma, M.; Möller, A.; Buhtz, H. Extraction of pigments and fatty acids from the green alga scenedesmus obliquus (chlorophyceae). Aquat. Ecol. 2000, 34, 119-126.

4. Barclay, W.R.; Meager, K.M.; Abril, J.R. Heterotrophic production of long chain omega-3 fatty acids utilizing algae and algae-like microorganisms. J. Appl. Phycol. 1994, 6, 123-129.

5. Chisti, Y. Biodiesel from microalgae. Biotechnol. Adv. 2007, 25, 294-306.

6. Mata, T.M.; Martins, A.A.; Caetano, N.S. Microalgae for biodiesel production and other applications: A review. Renew. Sust. Energ. Rev. 2010, 14, 217-232.

7. Radakovits, R.; Jinkerson, R.E.; Darzins, A.; Posewitz, M.C. Genetic engineering of algae for enhanced biofuel production. Eukaryot. Cell 2010, 9, 486-501.

8. Richmond, A.; Zhang, C.W. Optimization of a flat plate glass reactor for mass production of nannochloropsis sp. outdoors. J. Biotechnol. 2001, 85, 259-269.

9. Lee, S.; Yoon, B.; Oh, H. Rapid method for the determination of lipid from the green alga botryococcus braunii. Biotechnol. Tech. 1998, 12, 553-556.

10. Richmond, A. Basic culturing techniques. In Handbook of Microalgal Culture: Biotechnology and Applied Phycology; 1st ed.; Richmond, A., Ed.; Blackwell Publishing: Cornwall, UK, 2004.

11. Chen, Y.; Vaidyanathan, S. A simple, reproducible and sensitive spectrophotometric method to estimate microalgal lipids. Anal. Chim. Acta 2012, 724, 67-72. 
12. Collos, Y.; Mornet, F.; Sciandra, A.; Waser, N.; Larson, A.; Harrison, P.J. An optical method for the rapid measurement of micromolar concentrations of nitrate in marine phytoplankton cultures. J. Appl. Phycol. 1999, 11, 179-184.

13. Held P. Monitoring of Algal Growth Using Their Intrinsic Properties. Available online: http://www.biotek.com/resources/articles/monitoring-of-algal-growth-using-intrinsic properties.html (accessed on 11 July 2011).

14. AlgaeTorch-Chlorophyll and Cyanobacteria measurement. Available online: http://www. bbe-moldaenke.de/chlorophyll/algaetorch/ (accessed on 12 July 2013).

15. Unique Design of EXO Total Algae Sensor Combines Chlorophyll and Blue-green Algae for Greater Accuracy. Available online: http://www.exowater.com/blognow/blogDetail.php? Unique-Design-of-EXO-Total-Algae-Sensor-Combines-Chlorophyll-and-Blue-green-Algae-forGreater-Accuracy-3 (accessed on 12 July 2013).

16. 6131 and 6132 Blue-Green Algae Sensors (6-Series). Available online: http://www.ysi.com/ accessoriesdetail.php?6131-and-6132-Blue-Green-Algae-Sensors-6-Series-91（accessed on 12 July 2013).

17. Blue-Green Algae by Sensor Turner Designs. Available online: http://www.hachhydromet.com/ web/ott_hach.nsf/id/pa_blue-green_algae_by_turner_designs.html (accessed on 10 February 2012).

18. Briassoulis, D.; Panagakis, P.; Chionidis, M.; Tzenos, D.; Lalos, A.; Tsinos, C.; Berberidis, K.; Jacobsen, A. An experimental helical-tubular photobioreactor for continuous production of nannochloropsis sp. Bioresour. Technol. 2010, 101, 6768-6777.

19. López, M.C.G.; Sánchez, E.D.R.; López, J.L.C.; Fernández, F.G.A.; Sevilla, J.M.F.; Rivas, J.; Guerrero, M.G.; Grima, E.M. Comparative analysis of the outdoor culture of haematococcus pluvialis in tubular and bubble column photobioreactors. J. Biotechnol. 2006, 123, 329-342.

20. Marxen, K.; Vanselow, K.; Lippemeier, S.; Hintze, R.; Ruser, A.; Hansen, U. A photobioreactor system for computer controlled cultivation of microalgae. J. Appl. Phycol. 2005, 17, 535-549.

21. Meireles, L.A.; Azevedo, J.L.; Cunha, J.P.; Malcata, F.X. On-line determination of biomass in a microalga bioreactor using a novel computerized flow injection analysis system. Biotechnol. Prog. 2002, 18, 1387-1391.

22. Nedbal, L.; Trtílek, M.; Červený, J.; Komárek, O.; Pakrasi, H.B. A photobioreactor system for precision cultivation of photoautotrophic microorganisms and for high-content analysis of suspension dynamics. Biotechnol. Bioeng. 2008, 100, 902-910.

23. Sandnes, J.M.; Ringstad, T.; Wenner, D.; Heyerdahl, P.H.; Källqvist, T.; Gislerød, H.R. Real-time monitoring and automatic density control of large-scale microalgal cultures using near infrared (NIR) optical density sensors. J. Biotechnol. 2006, 122, 209-215.

24. Su, C.; Fu, C.; Chang, Y.; Nair, G.; Ye, J.; Chu, I.; Wu, W. Simultaneous estimation of chlorophyll a and lipid contents in microalgae by three-color analysis. Biotechnol. Bioeng. 2008, 99, 1034-1039.

25. Yao, Y.; Thommasson, J.A.; Ge, Y.; Sui, R. Improvement of an optical density sensor for algae pond monitoring and process control. ASABE 2012, doi:10.13031/2013.42323. 
26. Jones, S.B.; Zhu, Y.; Anderson, D.B.; Hallen, R.T.; Elliott, D.C.; Schmidt, A.J.; Albrecht, K.O.; Hart, T.R.; Butcher, M.G.; Drennan, C.; et al. Process Design and Economics for the Conversion of Algal Biomass to Hydrocarbons: Whole Algae Hydrothermal Liquefaction and Upgrading; Technical Report for Pacific Northwest National Laboratory: Richland, WA, USA, 2014.

27. Zhu, C.J.; Lee, Y.K. Determination of biomass dry weight of marine microalgae. J. Appl. Phycol. 1997, 9, 189-194.

28. Solovchenko, A.; Khozin-Goldberg, I.; Recht, L.; Boussiba, S. Stress-induced changes in optical properties, pigment and fatty acid content of nannochloropsis sp.: Implications for non-destructive assay of total fatty acids. Mar. Biotechnol. 2011, 13, 527-535.

29. Ogbonna, J.C.; Tanaka, H. Night biomass loss and changes in biochemical composition of cells during light/dark cyclic culture of Chlorella pyrenoidosa. J. Ferment. Bioeng. 1996, 82, 558-564.

(C) 2015 by the authors; licensee MDPI, Basel, Switzerland. This article is an open access article distributed under the terms and conditions of the Creative Commons Attribution license (http://creativecommons.org/licenses/by/4.0/). 